\title{
Ultrasound-Guided Preload Indices during Different Weaning Protocols of Mechanically Ventilated Patients and its Impact on Weaning Induced Cardiac Dysfunction
}

\author{
Dina Zeid*(D), Walid Ahmed (i), Randa Soliman, Abdou Alazab (D), Ahmed Samir Elsawy (D) \\ Department of Critical Care Medicine, Faculty of Medicine, Cairo University, Giza, Egypt
}

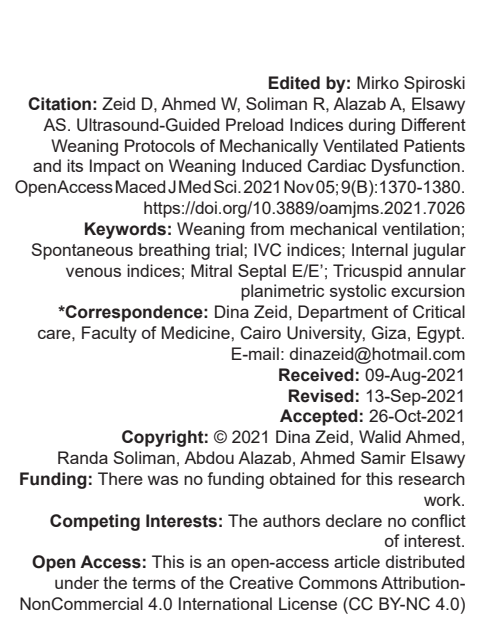

Introduction

Weaning is an important phase for the ventilated patient. The timing of weaning is essential; the least risk for a premature extubation is reintubation, with possibly unstable clinical situation and significant risk of nosocomial pneumonia [1].

Elevation of the left ventricle (LV) filling pressure can occur during weaning due to an increase in LV preload and/or decrease in LV compliance and/or increase in LV afterload. Previous studies showed that weaning might be associated with increase in filling pressures with a suggested increase in work of breathing and its effect on cardiac performance.

Pressure and volume change within the intrathoracic systemic venous compartment are accompanied by changes in extrathoracic veins such as in the intra-abdominal IVC or extra-thoracic internal jugular vein (IJV). Based on this linkage, we hypothesized that right heart function could be reflected by changes in IJV pressures as assessed by IJV diameter changes [2], [3], [4], [5].

\section{Patients and Methods}

This prospective observational study was conducted on 80 patients admitted to the Department of Critical Care Medicine, Faculty of Medicine, Cairo University, from November 2017 to September 2019. The study was approved by the Ethical Committee of Cairo University. Informed consent was obtained from the first-degree relative.

\section{Patients}

Patients were observed under assisted controlled mechanical ventilation for up to $48 \mathrm{~h}$ before they were considered ready to undergo an initial spontaneous breathing trial (SBT).

Patients were included in the weaning trial if they met the following criteria: Adult patients $>18$ years, improved the underlying condition of invasive mechanical ventilation, body temperature $<39^{\circ} \mathrm{C}$, hemoglobin level $>7 \mathrm{~g} / \mathrm{dl}, \mathrm{PaO}_{2}>60 \mathrm{mmHg}, \mathrm{FIO}_{2} \leq 40 \%$, PEEP $\leq 8 \mathrm{~cm} \mathrm{H}_{2} \mathrm{O}$, respiratory rate was $<35$ breaths/ 
min, systolic arterial pressure $>90 \mathrm{mmHg}$ (without need for/or high dose vasoactive drugs) and $<160 \mathrm{mmHg}$, no sedation, and stable neurological status [6].

Patients were excluded if they had inappropriate acoustic windows, arrhythmias, and impaired consciousness who cannot protect their airways. Those who were dependent on high $\mathrm{FiO}_{2}$ $>0.5$ and high PEEP (>8 $\mathrm{cm} \mathrm{H}_{2} \mathrm{O}$ ), on high doses of vasopressor, and/or inotropic support. Furthermore, patients whom were diagnosed with severe neuromuscular disorders.

All patients were subjected to detailed history taking, general and local clinical examination. They had laboratory investigations as complete blood count, liver and renal chemistry and blood gases on admission, before trial, and the end of weaning trial. Bedside twelve leads electrocardiogram was done and examined for any evidence of arrhythmia. Chest radiographs: were examined serially for all patients to detect progression and/or improvement of the underlying pathology. APACHE II and SOFA score in the $1^{\text {st }} 24 \mathrm{~h}$ [7], [8].

\section{SBT procedure}

Patients were divided randomly into two groups who were ready to start SBT either on pressure support ventilation (PS/CPAP pressure support $8 \mathrm{~cm}$ $\mathrm{H}_{2} \mathrm{O}$, CPAP $5 \mathrm{~cm} \mathrm{H} \mathrm{H}_{2} \mathrm{O}$ for 30 min or for T-piece with continuous oxygen source for $120 \mathrm{~min}$ [9]. Continuous hemodynamic monitoring, measuring, and recording of the parameters during two phases: assisted controlled ventilation and at the end of SBT either on PS/CPAP or T-piece with continuous oxygen supply.

Patients who succeeded to pass SBT were then extubated with continuous monitoring and observation for signs of failure of weaning for $48 \mathrm{~h}$.

Failure of the weaning process was defined as a failed SBT or the need for reintubation within $48 \mathrm{~h}$ following extubation. Hence, all patients included in the study were observed for $48 \mathrm{~h}$ after the SBT [10].

Transthoracic echocardiographic evaluation was done at bedside to all patients using TOSHIBA platinum Xario 200 series, with a probe PSU-30BT $3 \mathrm{MHz}$ with frequency range 1.8 4.8 $\mathrm{MHz}$ on assisted controlled ventilation and at the end of SBT. M-mode, two-dimensional (2D), Color flow mapping, Doppler measurements, and Tissue Doppler imaging (TDI) parameters were recorded. We used it to assess inferior vena cava indices

\section{LV global systolic function}

We assessed LV Global systolic function using M-mode modality in the long axis parasternal view for linear measurement of RV and LV [11].
The M-mode cursor was positioned at the level of the mitral valve leaflets tips to measure: -The right ventricular end-diastolic diameter, interventricular septal thickness in diastole, the left ventricular endsystolic (LVESd), and end-diastolic dimensions (LVEDd) (normally up to $5.6 \mathrm{~cm}$ ), posterior wall thickness.

LV fractional shortening percentage was calculated as:

[(LVEDd - LVESd)/LVEDd] × 100 (normally: 25-45\%) [11].

LV ejection fraction (EF). Systolic dysfunction was defined as EF below $50 \%$. LV systolic function was also measured using modified Simpson's method in the apical window [12].

\section{LV diastolic function}

We assessed LV diastolic function using mitral flow velocities that were obtained with the sample volume positioned between the tips of the mitral leaflets, where maximal flow velocity is recorded. For all measurements, five cycles were recorded using a sweep speed of $100 \mathrm{~mm} / \mathrm{s}$., We measured Peak early (E) and atrial (A) flow velocity $(\mathrm{cm} / \mathrm{s})$, E/A ratio.

TDI of the mitral annulus was obtained from the apical 4-chamber view. A 1.5-mm sample volume was placed at the lateral and septal mitral annulus.

Analysis was then performed for: Septal $E^{\prime}$ mitral: with normal value is $10.4 \pm 2.1 \mathrm{~cm} / \mathrm{s}$ [13]. Septal E/E' ratio: with normal value is $<8$ [13]. The recommended variables for identifying diastolic dysfunction and their abnormal cutoff values are annular $e^{\prime}$ velocity: septal $e^{\prime}<7 \mathrm{~cm} / \mathrm{s}$, lateral $e^{\prime}<10 \mathrm{~cm} / \mathrm{s}$, average $\mathrm{E} / \mathrm{e}^{\prime}$ ratio $>14$, LA volume index $>34 \mathrm{~mL} / \mathrm{m}^{2}$, and peak TR velocity $>2.8 \mathrm{~m} / \mathrm{s}$ [13]

\section{Right ventricular systolic function}

Right ventricular systolic function assessment was done using tricuspid annular planimetric systolic excursion (TAPSE) on M-mode using the 2D fourchamber view. The cursor was placed at the junction of tricuspid valve plan with the free wall of the RV, whereas data were averaged over five beats. A TAPSE measurement of $<16 \mathrm{~mm}$ is highly specific for $\mathrm{RV}$ dysfunction [14].

\section{Preload indices}

We evaluated cardiac preload using inferior vana caval indices and IJV indices. Each was recorded on assisted controlled mode, and at the end of mode of weaning either PS/CPAP or T-piece.

IVC collapsibility and distensibilty indices were recorded from subcostal view: The transducer position 
is just below the xiphisternum 1-2 cm to the right of the midline. After obtaining a 2-D image of the IVC entering the right atrium and verifying that the IVC visualization is not lost during movements of respiration, place a M-mode line through the IVC $1 \mathrm{~cm}$ caudal from its junction with the hepatic vein, and obtain a M-mode tracing then measure the maximum and minimum diameter of the IVC tracing [15], [16].

IVC distensibilty index is expressed as the difference between the value of the maximum diameter and the minimum diameter, divided by the minimum of the two values for mechanically ventilated patients using the formula (IVC d max - IVC $d \min$ )/IVC $d \min \times 100 \%$ [16].

The IVC collapsibility index (IVC ci) is expressed as the difference between the value of the maximum diameter and the minimum diameter, divided by the maximum of the two values. (IVC $\mathrm{d} \max -$ IVC $\mathrm{d}$ min)/ IVC d max $\times 100 \%$ for patients spontaneously breathing on T-piece [15].

IJV collapsibility and distensibilty indices were recorded using linear probe PLU-704 BT with Frequency range 2 11 $\mathrm{MHz}$. The IJV was measured using the $\mathrm{M}$ mode. The prescribed measurement technique was followed to determine the IJV anterior-posterior (AP) diameter during a respiratory cycle.

The IJV collapsibility index was calculated as IJV maximal AP diameter during expiration minus IJV maximal AP diameter during inspiration divided by the maximal AP diameter during expiration. This relation was reversed in mechanically ventilated patients [17].

The protocol used for the measurement of IJV collapsibility and distensibilty indices [17]: the patient's position is at 30 degree head elevation with the head slightly rotated to expose right or left IJV. We placed the transducer transversely across the patient neck, the area lateral to the cricoid cartilage.

IJV vessel identification was done by identifying 2 vessels lateral to the trachea and IJV was identified by compressibility, color flow or pulse wave Doppler with applying minimum pressure, enough to obtain an adequate ultrasound image of the right/left IJV then rotating the transducer clockwise or counter-clockwise to obtain the most circular cross-sectional image of the IJV through complete respiratory cycle.

We measured the Anteroposterior diameter during maximum and minimum distention during a respiratory cycle.

We calculated IJV collapsibility index $=($ IJV d $\max -$ IJV $d$ min)/IJV $d \max \times 100 \%$ for spontaneously breathing patients on T-piece [18].

IJV distensibilty index on mechanical ventilation was calculated $=(I J V d \max -I J V d \min ) / I J V d \min x$ $100 \% \%$ [17].

\section{Statistical methods}

Data were collected and analyzed using the statistical package SPSS (Statistical Package for the Social Science; SPSS Inc., Chicago, IL, USA) version 22. Numerical values were expressed in Mean \pm SD format. Frequency and relative frequency were mentioned for categorical data. Comparative analysis was run for non-parametric variable using Mann-Whitney tests. Serial paired comparisons were done using Wilcoxon signed-rank. Chi-square $(\chi 2)$ test was performed for comparing categorical data. ROC curve was constructed with area under curve analysis performed to detect best cutoff value for the detection of success of $1^{\text {st }}$ SBT. $p<0.05$ were considered as statistically significant.

\section{Results}

Our study was conducted as a prospective randomized study at the critical care medicine department, faculty of medicine Cairo University, included 80 intubated and mechanically ventilated patients who were eligible for SBT between November 2017 and September 2019.

The study population were divided into two groups according to mode of weaning, and patients were assigned randomly into one of the weaning processes.

Group I $(n=40): 40$ patients met the readiness criteria to start SBT using pressure support ventilation (PS/CPAP pressure support $8 \mathrm{~cm} \mathrm{H}_{2} \mathrm{O}$, CPAP $5 \mathrm{~cm} \mathrm{H}_{2} \mathrm{O}$ for $30 \mathrm{~min}$. (CPAP group) Group II $(n=40)$ : 40 patients met the readiness criteria to start SBT using T-piece with continuous oxygen source for $120 \mathrm{~min}$ (T-piece group). separately.

Each group will be analyzed and discussed

Table 1: Comorbidities and their prevalence for CPAP group

\begin{tabular}{llll}
\hline Weaning & Failed group & Success group & p value \\
\hline Hypertensive & $21(100 \%)$ & $17(89 \%)$ & 0.22 \\
Diabetic & $19(90 \%)$ & $3(15 \%)$ & $<0.005$ \\
\hline
\end{tabular}

\section{Group I (CPAP)}

This group included 40 patients, where 19 patients $(47.5 \%)$ succeeded to pass the weaning trial, 11 patients failed $(27.5 \%)$ and 10 patients (25\%) were reintubated.

\section{Demographic data}

The mean age of the studied patients was 59.17 \pm 16.7 years. Succeeded group had age of 50.4 years \pm 20.3 versus $67.1 \pm 6.3$ with a statistically significance 
$p=0.003$. In the studied population, there were 13 male representing $33 \%$ and 27 females representing $67 \%$.

There was a significant difference between males and females regarding failure rates where males showed higher failure rates ( $76 \%$ vs. $40 \%$ in females, $p=0.034$ ).

\section{Clinical data of the patients}

The Most prevalent comorbidities among the studied population was hypertension, 38 patients were hypertensive (95\%), followed by diabetes (22 patients, $55 \%$ ) as shown in Table 1.

Table 2: APACHE II and SOFA scores and their statistically significance

\begin{tabular}{lllll}
\hline Score & CPAP & Succeeded & Failed & p value \\
\hline APACHE II & $18 \pm 4$ & $16 \pm 3$ & $21 \pm 3$ & $<0.001$ \\
SOFA & $7 \pm 2$ & $7 \pm 2$ & $8 \pm 2$ & 0.313 \\
\hline
\end{tabular}

\section{Laboratory values and clinical scores}

There is statistically significant difference between the succeeded and failed groups regarding the following lab: $\mathrm{pH}$ and $\mathrm{pO}_{2}$ before SBT trial. As well as $\mathrm{pCO}_{2}$ and $\mathrm{SO}_{2}$ at the end of SBT trial.

APACHE II score showed statistically significant difference between the succeeded and failed groups (16 \pm 3 vs. $21 \pm 3$ ) with $p<0.001$ as shown in Tables 2-4.

Table 3: Blood gases before SBT and significance in outcome of SBT

\begin{tabular}{lllll}
\hline Lab values & CPAP & Failed & Succeeded & p value \\
\hline $\mathrm{pH}$ & $7.37 \pm-0.12$ & $7.37 \pm 0.01$ & $7.38 \pm-0.01$ & 0.003 \\
$\mathrm{pCO}_{2}$ & $41.2 \pm-7.3$ & $42.9 \pm 7.5$ & $39.3 \pm 6.9$ & 0.126 \\
$\mathrm{pO}_{2}$ & $75.6 \pm 8.5$ & $79.4 \pm 9.1$ & $71.4 \pm 5.5$ & 0.002 \\
$\mathrm{HCO}_{3}$ & $25.5 \pm 4.5$ & $26.7 \pm-4.1$ & $24.1 \pm 4.6$ & 0.058 \\
$\mathrm{SO}_{2}$ & $95.3 \pm 1.2$ & $95.2 \pm 1.1$ & $95.4 \pm 1.2$ & 0.544 \\
\hline SBT: Start spontaneous breathing trial & &
\end{tabular}

\section{Echocardiographic data}

Diastolic mitral inflow assessment as indices for cardiac dysfunction

We recorded Mitral E/A and Septal E/E during assisted controlled ventilation and CPAP trial. A statistically significant difference was found between the succeeded and failed groups regarding E/A, Septal E/E' during CPAP SBT with $p=0.015$ and 0.001 respectively. This is shown in Table 5.

ROC curve was plotted to determine the cuff off values to predict weaning failure on CPAP mode for CPAP group showed as illustrated in Figure 1 and Table 6

- $\quad$ Mitral E/A cut off value $\geq 0.88$ with sensitivity $71 \%$ and specificity $68.4 \%$, AUC 0.7

- $\quad$ Mitral Septal E/E' Cut off value $\geq 6.1$ with sensitivity $81 \%$ and specificity $84.2 \%$, AUC 0.73

- $\quad$ RV TAPSE Cut off value $\leq 22.5$ with sensitivity $43 \%$ and specificity $68 \%$, AUC 0.45 .
Table 4: Blood gases after SBT and significance in outcome of SBT

\begin{tabular}{lllll}
\hline Lab & CPAP & Failed & Succeeded & p value \\
\hline $\mathrm{pH}$ & $7.37 \pm 0.4$ & $7.37 \pm 0.05$ & $7.39 \pm 0.02$ & 0.266 \\
$\mathrm{PCO}_{2}$ & $43.5 \pm 12.5$ & $47.8 \pm 14.1$ & $38.7 \pm 8.7$ & 0.021 \\
$\mathrm{pO}_{2}$ & $72.2 \pm 8.1$ & $71.7 \pm 9.7$ & $72.7 \pm 5.8$ & 0.68 \\
$\mathrm{HCO}_{3}$ & $25.6 \pm 5.1$ & $26.8 \pm 5.4$ & $24.3 \pm 4.4$ & 0.126 \\
$\mathrm{SO}_{2}$ & $93.9 \pm 2.6$ & $92.2 \pm 2.3$ & $95.7 \pm 1.6$ & $<0.001$ \\
\hline SBT: Start spontaneous breathing trial. & & &
\end{tabular}

\section{Preload indices during assisted controlled ventilation and CPAP trial}

We assessed preload indices during assisted controlled ventilation and CPAP trial. A statistically significant difference was found between the succeeded and failed groups regrading IJV distensibilty index on $A C V$ and inferior vena cava distensibilty index on ACV and during CPAP SBT as shown in Table 7.

ROC curve was plotted to determine cuffoff value for CPAP group to predict weaning failure during weaning CPAP mode. IJV distensibilty index cut off value $\geq 66 \%$ with sensitivity $100 \%$ and specificity $31.6 \%$, AUC 0.49 , IVC distensibilty index cutoff value $\geq 66.5 \%$ with sensitivity $100 \%$ and specificity $68.4 \%$, AUC 0.85 as shown in Table 8 and Figure 2.

Mitral Septal E/E' on CPAP was correlated to IVC distensibilty index during weaning on CPAP $(r=0.599, P$ value $<0.001)$. TAPSE was correlated to IVC distensibilty index during weaning on CPAP ( $r=$ $-0.42, \mathrm{P}$ value $=0.007$ ) as shown in Table 9 .

RV function by TAPSE showed no statistically significance between the succeeded and failed groups as shown in Table 10.

\section{Group II (T-piece)}

This group included 40 patients, where 22 patients $(55 \%)$ succeeded to pass the weaning trial, 9 patients $(22.5 \%)$ failed, and 9 patients $(22.5 \%)$ were reintubated.

Table 5: Mitral flow indices on ACV and during CPAP SBT trial

\begin{tabular}{lllll}
\hline Parameters & CPAP & Failed & Success & p value \\
\hline E/A ACV & $0.93 \pm 0.37$ & $0.97 \pm 0.47$ & $0.89 \pm 0.25$ & 0.49 \\
E/A CPAP & $0.94 \pm 0.36$ & $1.07 \pm 0.42$ & $0.8 \pm 0.21$ & 0.015 \\
Septal E/E' ACV & $6.01 \pm 2.4$ & $5.7 \pm 2.7$ & $6.4 \pm 2.1$ & 0.38 \\
Septal E/E' CPAP & $6.9 \pm 2.2$ & $8 \pm 2.02$ & $5.87 \pm 1.88$ & 0.001 \\
\hline \multicolumn{2}{l}{ SBT: Start spontaneous breathing trial. }
\end{tabular}

\section{Demographic data}

The mean age of the studied patients was $58.1 \pm 0.4$ years. Succeeded group was younger (51.9 \pm 21.2 vs. $65.7 \pm 5.7$ ) with statistically significance $p=0.007$. In the studied population, there were 15 males representing $37 \%$ and 25 females representing $63 \%$. There was a significant difference between males and females regarding failure rates where males showed higher failure rates $(11 / 15$ versus $7 / 25, p=0.007)$ as shown in Table 11. 
Table 6: Mitral flow and TAPSE indices during CPAP SBT to predict weaning failure

\begin{tabular}{llllll}
\hline Weaning failure CPAP & AUC & Significance & Cutoff & Sensitivity (\%) & Specificity (\%) \\
\hline E/A CPAP & 0.703 & 0.028 & 0.88 & 71.4 & 68.4 \\
Septal E/E' CPAP & 0.732 & 0.012 & 6.1 & 81.0 & 84.2 \\
TAPSE CPAP & 0.456 & 0.636 & 22.5 & 42.9 & 68.4 \\
\hline TAPSE: Tricuspid annular planimetric systolic excursion. & & &
\end{tabular}

\section{Clinical data of the patients}

The most prevalent comorbidities among the studied population was hypertension; 33 from 40 patients were hypertensive $(83 \%)$, which is insignificant then diabetes; 18 from 40 were diabetic $(45 \%)$ where only 3 diabetic patients succeeded with statistically significance $p=0.007$ as shown in Table 12 . Table 7: Preload indices for CPAP group during ACV and CPAP SBT trial

\begin{tabular}{lllll}
\hline Parameters & CPAP & Failed & Succeed & p value \\
\hline IJV di ACV & $0.81 \pm 0.25$ & $0.89 \pm 0.29$ & $0.72 \pm 0.17$ & 0.032 \\
IJV di CPAP & $0.84 \pm 0.19$ & $0.85 \pm 0.17$ & $0.83 \pm 0.21$ & 0.783 \\
IVC di ACV & $0.8 \pm 0.25$ & $0.87 \pm 0.29$ & $0.72 \pm 0.17$ & 0.052 \\
IVC di CPAP & $0.78 \pm 0.29$ & $0.95 \pm 0.23$ & $0.6 \pm 0.24$ & $<0.001$ \\
\hline
\end{tabular}

\section{Laboratory value and clinical scores}

Statistically significant difference was found between the succeeded and failed groups regarding $\mathrm{PO}_{2}$ and $\mathrm{HCO}_{3}$, before SBT trial and $\mathrm{HCO}_{3}$ and $\mathrm{SO}_{2}$ end of SBT trial.

APACHE II score showed a statistically significant difference between the succeeded and failed groups in SBT $p=0.03$ while SOFA score did not show significance as shown in Tables 13-15.

Table 8: ROC analysis for preload indices during CPAP SBT to predict weaning failure. CPAP group

\begin{tabular}{llllll}
\hline Weaning failure CPAP & AUC & Significance & Cutoff (\%) & Sensitivity (\%) & Specificity (\%) \\
\hline IJV distensibilty index & 0.499 & 0.989 & 66 & 100.0 & 31.6 \\
IVC distensibilty index & 0.857 & 0.000 & 66.5 & 100.0 & 68.4 \\
\hline
\end{tabular}

\begin{tabular}{llll} 
IVC distensibilty index & 0.857 & 0.000 & 66.5 \\
\hline SBT: Start spontaneous breathing trial, IJV: Internal jugular vein.
\end{tabular}

\section{Echocardiographic data}

Diastolic mitral inflow assessment as indices for cardiac dysfunction

We recorded Mitral E/A, and Septal E/E' during assisted controlled ventilation, and T-piece SBT trial.

Mitral Septal E/E' during T-piece showed statistically significant in Succeeded group $p=0.001$ as shown in Table 16.

ROC curve was plotted to determine cuff off value for T-tube group to predict weaning failure on T-piece as shown in Table 17 and Figure 3.

- Mitral E/A T-tube Cut off value $\geq 0.6$ with sensitivity $94 \%$ and specificity $27.3 \%$, AUC 0.48

- $\quad$ Mitral Septal E/E' Cut off value $\geq 5.8$ with sensitivity $83 \%$ and specificity $90.9 \%$,AUC 0.83

- $\quad$ RV TAPSE cut off value $\leq 19.5$ with sensitivity $61 \%$ and specificity $68 \%$, AUC 0.59 .
Table 9: Correlation mitral septal E/E' and TAPSE during weaning to IVC di

\begin{tabular}{ll}
\hline CPAP & IVC distensibilty index weaning \\
\hline Septal E/E' weaning & \\
r & 0.599 \\
p value & 0.000 \\
TAPSE weaning & \\
$r$ & -0.42 \\
p value & 0.007 \\
\hline TAPSE: Tricuspid annular planimetric systolic excursion. &
\end{tabular}

\section{Preload indices during assisted controlled} ventilation and T-piece trial

IVC ci was statistically significant in success of weaning with $p=0.005$ during SBT with T-piece. IJV collapsibility index did not show any statistically significance in success of SBT trial as shown in Table 18.

ROC curve was plotted to determine cuff off value for T-tube group to predict weaning failure during weaning as shown in Table 19 and Figure 4.

- $\quad$ IJV collapsibility index cut off value $\geq 52.5 \%$ with sensitivity $22 \%$ and specificity $95.5 \%$, AUC 0.52

- $\quad$ IVC ci cut off value $\geq 45.5 \%$ with sensitivity $72 \%$ and specificity $86 \%$, AUC 0.73 .

Mitral Septal E/E' was correlated to IVC collapsibility index during weaning on T-tube $(r=0.45, P$ value $=0.003)$ as shown in Table 20.

Table 10: TAPSE during ACV and CPAP SBT in CPAP group

\begin{tabular}{lllll}
\hline Parameters & CPAP & Failed & Succeeded & p value \\
\hline TAPSE ACV & $21.8 \pm 3.2$ & $21.8 \pm 3.6$ & $21.8 \pm 2.8$ & 0.93 \\
TAPSE CPAP & $21.9 \pm 4.1$ & $21.8 \pm 4.1$ & $22.2 \pm 4.3$ & 0.77 \\
\hline
\end{tabular}

TAPSE: Tricuspid annular planimetric systolic excursion.

\section{$R V$ function assessment by TAPSE}

RV function by TAPSE showed no statistically significance in success of weaning success as shown in Table 21.

Table 11: Gender distribution, \% of outcome and significance

\begin{tabular}{lllll}
\hline Gender & T-piece $(\%)$ & Failed $(\%)$ & Succeeded $(\%)$ & $\mathrm{p}$ \\
\hline Female & $25(63)$ & $7(38)$ & $18(81)$ & 0.007 \\
Male & $15(37)$ & $11(62)$ & $4(19)$ & 0.007 \\
\hline
\end{tabular}

\section{Discussion}

We aimed to study the hemodynamic changes and preload indices occurring during different modes of weaning from MV starting through changes of LV compliance and its reflection over Mitral flow velocities by performing a focused trans-thoracic echocardiography examination. 
Table 12: Comorbidities and prevalence

\begin{tabular}{lllll}
\hline Parameters & T-piece & Failed group $(\%)$ & Succeeded group $(\%)$ & $\mathrm{p}$ \\
\hline Diabetic & 18 & $15(83)$ & $3(13)$ & 0.007 \\
hypertensive & 33 & $16(88)$ & $17(77)$ & 0.2 \\
\hline
\end{tabular}

We used easy and non-invasive tools in our study. We focused on data with maximum benefit, quickest to obtain with minimal stress on the study patients who were already stressed during weaning from mechanical ventilation.

Table 13: Clinical scores and outcome

\begin{tabular}{lllll}
\hline Lab & T-piece & Succeeded & failed & p value \\
\hline APACHE II & $19.6 \pm 6$ & $17.2 \pm 3.2$ & $21.7 \pm 7.5$ & 0.018 \\
SOFA & $7 \pm 2$ & $7 \pm 2$ & $7 \pm 2$ & 0.905 \\
\hline
\end{tabular}

In our study, the patients who were intubated and mechanically ventilated and met the readiness criteria for weaning were included, we randomly divided the patients to do SBT through T-piece for $120 \mathrm{~min}$ or Pressure support for $30 \mathrm{~min}$ [9], [18].

Table 14: Blood gases on ACV before T -piece SBT

\begin{tabular}{lllll}
\hline Lab & T-piece & Failed & Success & p value \\
\hline $\mathrm{pH}$ & $7.37 \pm-0.12$ & $7.37 \pm 0.01$ & $7.37 \pm 0.01$ & 0.438 \\
$\mathrm{pCO}_{2}$ & $41.6 \pm 7.8$ & $43.5 \pm 7.8$ & $40 \pm 7.5$ & 0.155 \\
$\mathrm{pO}_{2} \mathrm{HCO}_{3}$ & $73.3 \pm 7.8$ & $76.4 \pm 9.4$ & $70.8 \pm 5.4$ & 0.034 \\
$\mathrm{SO}_{2}$ & $25.1 \pm 5$ & $27.2 \pm 3.7$ & $23.3 \pm 5.4$ & 0.013 \\
& $95 \pm-1.3$ & $95.2 \pm 1.1$ & $94.0 \pm 1.4$ & 0.464 \\
\hline
\end{tabular}

The success rate of SBT in our study was $47.5 \%$ in CPAP group, and $55 \%$ in T-piece group with $p=0.6$, the rate of success in other trials was very variable. Similar to our rate success rate was $55 \%$, in Liu et al., who monitored 283 consecutive SBTs (SBT; T-piece trial) performed in 81 patients [19].

Table 15: Blood gases at the end of SBT trial on T-piece

\begin{tabular}{lllll}
\hline Lab & T-piece & Failed & Success & p value \\
\hline $\mathrm{pH}$ & $7.36 \pm 0.38$ & $7.37 \pm 0.04$ & $7.37 \pm 0.04$ & 0.594 \\
$\mathrm{PCO}_{2}$ & $45.2 \pm 13.2$ & $49.1 \pm 14.5$ & $42.1 \pm 11.6$ & 0.096 \\
$\mathrm{pO}_{2}$ & $71.7 \pm 7.9$ & $71.8 \pm 9.2$ & $71.7 \pm 6.9$ & 0.984 \\
$\mathrm{HCO}_{3}$ & $25.2 \pm 5.3$ & $27.2 \pm 4.5$ & $23.5 \pm 5.3$ & 0.026 \\
$\mathrm{SO}_{2}$ & $93.6 \pm 2.2$ & $92.78 \pm 2.1$ & $94.3 \pm 2.2$ & 0.033 \\
\hline SBT: Start spontaneous breathing trial. & & &
\end{tabular}

A lot of studies done to demonstrate the different types of SBT, Sanfilippo et al. conducted systematic review to clarify the preferable SBT mode (T-piece or pressure support ventilation; the conclusion was that SBT technique did not influence weaning success [20].

Table 16: Mitral flow indices on ACV and during T-piece

\begin{tabular}{lllll}
\hline Mitral indices & T-piece & Failed & Success & P value \\
\hline E/A ACV & $0.78 \pm 0.24$ & $0.74 \pm 0.22$ & $0.82 \pm 0.26$ & 0.341 \\
E/A CPAP & $0.85 \pm 0.22$ & $0.86 \pm 0.23$ & $0.85 \pm 0.22$ & 0.887 \\
Septal E/E' ACV & $5.7 \pm 2.5$ & $4.94 \pm 2.6$ & $6.34 \pm 2.37$ & 0.086 \\
Septal E/E' T-piece & $6.1 \pm 2.2$ & $8 \pm 2$ & $5.87 \pm 1.88$ & 0.001 \\
\hline
\end{tabular}

Subirà et al. who studied 1153 patients under Successful extubation occurred in 473 patients $(82.3 \%)$ in the pressure support ventilation group and 428 patients $(74.0 \%)$ in the T-piece group (difference, $8.2 \%$; 95\% Cl, 3.4\%-13.0\%; $P=0.001$ ) [9].

The difference in success rates may be due to heterogeneity in patients' demographic data and comorbidities.
Table 17: ROC analysis for Mitral flow indices and TAPSE on T-piece

\begin{tabular}{llllll}
\hline $\begin{array}{l}\text { Weaning failure } \\
\text { T-tube }\end{array}$ & AUC & Significance & Cutoff & Sensitivity (\%) & Specificity (\%) \\
\hline E/A T-tube & 0.487 & 0.892 & 0.61 & 94.4 & 27.3 \\
$\begin{array}{l}\text { Septal E/E' } \\
\text { T-tube }\end{array}$ & 0.826 & 0.000 & 5.8 & 83.3 & 90.9 \\
TAPSE T-tube & 0.597 & 0.295 & 19.5 & 61.1 & 68.2 \\
\hline TAPSE Tricuspid & & & &
\end{tabular}

Regarding Age in both groups, succeeded patients were younger (50.4 years \pm 20.3 vs $67.1 \pm 6.3$ in CPAP group)(51.9 \pm 21.2 vs $65.7 \pm 5.7$ in T-piece group) with statistically significance $P$ value 0.003 . This was similar to Jinglun et al. (2016) [19]. Amarja et al. (2019) [21] and Subira et al. (2019) [9] where succeeded groups were younger but statistically insignificant.

Table 18: IVC distensibilty index, IVC collapsibility index, IJV distensibilty index and IJV collapsibility index on ACV and t-piece SBT

\begin{tabular}{lllll}
\hline $\begin{array}{l}\text { Preload } \\
\text { indices }\end{array}$ & T piece & Failed & Succeed & p value \\
\hline IJV di ACV & $0.41 \pm 0.84$ & $0.43 \pm 0.01$ & $0.39 \pm 0.1$ & 0.170 \\
IJV CI T-piece & $0.44 \pm 0.12$ & $0.43 \pm 0.14$ & $0.45 \pm 0.1$ & 0.603 \\
IVC di ACV & $0.41 \pm 0.84$ & $0.43 \pm 0.01$ & $0.39 \pm 0.1$ & 0.170 \\
IVC Ci T-piece & $0.41 \pm 0.9$ & $0.46 \pm 0.1$ & $0.37 \pm 0.1$ & 0.005 \\
\hline IJV: Internal jugular vein, SBT: Start spontaneous breathing trial. & &
\end{tabular}

Diabetic patients showed high weaning failure rates in our study in both groups and this was similar to Moschietto et al. (2012) on PS-SBT [22]; this was disconcordant to Ahlem et al. (2018) [23] who showed that diabetic patients included in the study didn't reach statistically significant difference as risk factor for weaning failure ( $p$ value $=0.5$ ).

Table 19: ROC analysis showing IVC and IJV ci on T-piece

\begin{tabular}{llllll}
\hline Weaning failure T-tube & AUC & Significance & $\begin{array}{l}\text { Cutoff } \\
(\%)\end{array}$ & $\begin{array}{l}\text { Sensitivity } \\
(\%)\end{array}$ & $\begin{array}{l}\text { Specificity } \\
(\%)\end{array}$ \\
\hline IJV collapsibility index & 0.525 & 0.786 & 52.5 & 22.2 & 95.5 \\
IVC collapsibility index & 0.737 & 0.011 & 45.5 & 72.2 & 86.4 \\
\hline IJV: Internal jugular vein. & & & & &
\end{tabular}

APACHE II Score in CPAP trial group was $18 \pm 4$ and, failed group showed higher value 21 \pm 3 in comparison to succeeded group $16 \pm 3$ with $p<0.001$.

In T-piece trial group APACHE II score $19.6 \pm 6$. Failed group showed higher value $21 \pm 7$ in comparison to succeeded group $17.2 \pm 3.2$ with $p<0.018$.

While SOFA score in both groups did not show any statistically significant difference between the succeeded and failed groups.

Table 20: Correlating mitral septal E/E' to IVC Ci on T-tube

\begin{tabular}{lll}
\hline T-tube & Correlation & IVC collapsibility index weaning \\
\hline Septal E/E' weaning & $\mathrm{R}$ value & 0.457 \\
& $\mathrm{p}$ value & 0.003 \\
\hline
\end{tabular}

Our results were similar to Anna et al. (2017) which studied 130 consecutive hospitalized patients, APACHE II score was assessed based on the worst values taken during the first 24 hours after admission. Among survivors ( $n=115), 88.2 \%$ were successfully liberated from mechanical ventilation and $60.9 \%$ from tracheostomy. APACHE II failed to predict weaning from mechanical ventilation (area under the receiveroperating characteristic curve [AUROC] $=0.534 ; 95 \%$ 
confidence interval [CI]: 0.439-0.628; $\mathrm{p}=0.65$ ) and tracheostomy tube removal (AUROC $=0.527 ; 95 \% \mathrm{Cl}$ : $0.431-0.621 ; p=0.63),(p=0.41)$. APACHE II couldn't predict weaning outcome in patients requiring PMV [24].

Our results were similar to Bien et al. (2016) which studied 195 patient with 150 were successfully extubated and 45 were not. Subjects who were unsuccessfully weaned from MV had significantly higher APACHE II $(7.65 \pm 4.0 .2 \pm 3.6, p<0.001)$ and SOFA (3.20 \pm 1.94 and $11.69 \pm 3.10, p<0.001)$ scores [25].

Table 21: TAPSE before and after SBT in both succeeded and failed groups

\begin{tabular}{lllll}
\hline TAPSE & T-piece & Failed & Succeeded & p value \\
\hline TAPSE ACV & $21.2 \pm 3.7$ & $21.9 \pm 4.4$ & $20.7 \pm 3.1$ & 0.298 \\
TAPSE T-piece & $19.9 \pm 3.2$ & $20.6 \pm 4.1$ & $19.4 \pm 2.2$ & 0.268 \\
\hline \multicolumn{7}{l}{ TAPSE: Tricuspid annular planimetric systolic excursion. }
\end{tabular}

In CPAP trial; Succeeded group showed higher $\mathrm{pH}$ lower $\mathrm{PCO}_{2}$, lower $\mathrm{PO}_{2}$, before trial and higher $\mathrm{SO} 2$ at the end of trial ( $p=0.003,0.02,0.002$ and <0.001) respectively.

In T- piece trial; Succeeded group showed lower $\mathrm{PO}_{2}$, before trial, lower $\mathrm{HCO}_{3}$ before and after trial and higher $\mathrm{SO}_{2}$ at the end of trial $(\mathrm{p}=0.034,0.01,0.02$, 0.03 respectively).

Metwally et al. (2018) who studied and divided 80 patients with COPD into two groups: group I included 40 patients who were weaned off by PSV mode and group II included 40 patients when there was no significant difference regrading partial arterial oxygen pressure, partial arterial carbon dioxide pressure, and arterial oxygen saturation at the end of PSV mode in both groups. A significant decline in partial arterial oxygen pressure and arterial oxygen saturation and increase in partial arterial carbon dioxide pressure were observed in group II patients after adding T-piece trial [26].

Jinglun-Liu et al. (2016) studied 283 SBT on t-piece and showed similar results regarding $\mathrm{PCO} 2$ which was significantly higher in patients who failed SBT [19].

Schiefbien et al. (2011) patients whose weaning was successful showed higher $\mathrm{PaO} 2$ and $\mathrm{SaO} 2$ in both groups [27].

Mitral Septal E/E' during CPAP trial showed statistically significant difference in with Cut off value of $\geq 6.1$ (sensitivity $81 \%$ and specificity $84.2 \%$, AUC 0.73) for predicting weaning failure which was concordant to Moschietto et al. [22] who studied 68 patients from which 20 patients failed.The failed group showed higher E/Ea with cut of value of 14.5 with a sensitivity of $75 \%$ and a specificity of $95.8 \%$. that was similar to our study during Assisted controlled mode A cutoff $\geq 12.6$ was associated with the highest diagnostic accuracy and predicted weaning failure with a sensitivity of $60 \%$ and a specificity of $95.8 \%$, while in our study, ROC analysis for Mitral flow Septal did not predict weaning failure on ACV mode [22] and disconcordant to Amarja et al. (2019) who studied pre and post-extubation for both failed and successful extubations using PS CPAP mode, pre extubation assessment $E / e^{\prime}(7.68$ vs. 8.21, $p=0.45)$ was not found as a statistically significant parameter [28].

In our study, Mitral E/A during CPAP showed statistically significant in Succeeded group with $p=0.015$ Cut off value $\leq 0.88$ (sensitivity $71 \%$ and specificity $68.4 \%$, AUC 0.7) which was disconcordant to Haji et al. that measured mitral flow E/A at the beginning of the weaning trial and there was no statistically significant difference between the succeeded and failed groups [29].

Also Mitral E/A on ACV was correlated to E/A during weaning on CPAP ( $r=0.73$ and $p<$ 0.001 ) and Mitral Septal E/E' on ACV was correlated to Mitral Septal E/E' during weaning on CPAP ( $r=$ 0.41, $p=0.009$ ).

Recent published data have demonstrated a positive association between the echocardiographic measurements of diastolic failure, in particular $E / E^{\prime}$, and weaning failure [22], [30], [31], [32]. E/E' is a marker of left atrial pressure, left ventricular diastolic pressure. $E / E^{\prime}$ is well correlated with pulmonary artery occlusion pressure [33]. However, this correlation in the operating room setting was debatable [34]. E/E' range of cut-off values of $7-14$ has been suggested for determining patients at risk of failing weaning from mechanical ventilation [30], [31], [32].

While In T-piece group, Mitral Septal E/E' Cut off value to predict weaning failure was $\geq 5.8$ with sensitivity $83 \%$ and specificity $90.9 \%$, AUC 0.83, Mitral Septal E/E' on ACV was correlated to Mitral Septal E/E' during weaning on T-tube $(r=0.34, p=0.02)$ to predict failure weaning,which was similar to Liu et al. who studied Mitral flow E/E' for patients before and after the SBT Mean E/E'10.5 \pm 4.3 for failed group versus $E / E$ $8.8 \pm 3.2$ with $p<0.01$ [19].

Also in Konomi et al. study, 22 succeeded and 12 failed to wean. No statistically significant differences were observed in the Doppler echocardiographic variables (E, A, E/A, septal e', septal E/e') between the weaning success and failure patients at baseline.

LV diastolic dysfunction was significantly associated with weaning failure $(p<0.001)$ and was the best independent risk factor for weaning failure [35].

This was contradictory to Schifelbain et al. who studied 24 critical patients to analyze changes in cardiac function during weaning from MV. He used two different weaning methods: pressure support ventilation and T-tube. He did not find any differences between Doppler echocardiography and cardiorespiratory variables during pressure support ventilation and T-piece either in success or failure [27].

RV function by TAPSE showed no statistically significance in weaning success in both groups which 
was concordant to Saeed et al. (2018) [36] who studied 50 mechanically ventilated chronic obstructive pulmonary disease patients. Chest ultrasonography for the assessment of diaphragmatic mobility in addition to echocardiography was performed on different modes of mechanical ventilation in the same session at any time since mechanical ventilation. There was an insignificant correlation between echocardiography in ejection fraction, RVSP, TAPSE, and different modes of mechanical ventilation. This was in agreement with Luciele et al. (2011) and Alexandre et al (2005) who found that no echocardiographic differences were observed between PSV and T-tube [27], [37], this was similar to Ahlem et al. (2018) who found that there was no difference in either TAPSE or SPAP between the two groups at baseline and before/after T-tube. This likely reflects the absence of pulmonary hypertension induced by T-tube test [23].

In our study, the T-piece group, IVC ci was 0.46 \pm 0.1 in the failed group and $0.37 \pm 0.1$ in the succeeded group which showed statistically significant difference in success of weaning with $p=0.005$ during SBT with T-piece IVC ci Cut off value $45.5 \%$ with sensitivity $72 \%$ and specificity $86 \%$, AUC 0.73 .

IJV collapsibility index didn't show any statistically significance in success of SBT trial between the failed and succeeded groups this maybe related to methodological issues as collapsibility indices weren't tested. which was disconcordant to Ahlem et al. (2018) Collapsibility index of IVC was similar before and after T-piece test, suggesting more that this parameter represents a dynamic preload index rather than hyperinflation [23]. Also Daif et al. (2018) There was no statistically significant relation between inferior vena cava (IVC) collapsibility index and SBT outcome in patients with COPD [38] and Airapetian et al. (2015) where echocardiography and Doppler ultrasound were used to record the stroke volume (SV), cardiac output (CO) and IVC collapsibility index (IVC ci) at baseline, after a passive leg-raising maneuver (PLR) which showed that neither the IVC diameter nor IVC variability $(P=0.4)$ accurately predict fluid responsiveness in spontaneously breathing patients hospitalized in the ICU [39].

Bauman et al. found that The IVC and IJV collapsibility had a significantly high correlation in the setting of spontaneous breathing ( $r 2=0.86, p<0.01$ ) [40].

In our study, Mitral Septal E/E' during weaning on T-tube was correlated to IVC ci during weaning on T-tube $(r=0.45, p=0.003)$.

Regarding, CPAP group in our study, IJV distensibilty index during $A C V$ was $0.72 \pm 0.17$ in the succeeded group and $0.89 \pm 0.29$ in the failed group which showed statistically significant difference $p=0.03$,
IVC distensibilty index during ACV was $0.72 \pm 0.17$ in the succeeded group and $0.87 \pm 0.29$ in the failed group with statistically significant difference $p=0.05$

IVC distensibilty index during CPAP was $0.6 \pm$ 0.24 in the succeeded group and $0.95 \pm 0.2 w$ in the failed group with statistically significant difference $p<0.001$.

This was disconcordant to Ahlem, 2018 [23] that IVC Di index didn't show any significance in CPAP group weaning and Juhl-Olsen et al. showed in a small study that at least IVC-C did not seem to be a valid measure of preload status during positive pressure ventilation [41]

Tongyoo et al. who aimed to investigate the efficacy of echocardiography during SBT with low-level pressure support for predicting weaning failure among medical critically ill patients. Inferior vena cava maximum diameter $>17$ and E/Ea ratio $\geq 14$ independently predict weaning failure in patients with preserved LV systolic function while IVC distensibilty index was statistically insignificant [42].

Also Saritaş et al. studied IVC di had a more accurate predictive role in predicting volume status when compared with the CI-IVC and $\triangle I V C$, and may be used reliably with positive pressure supports. The median value for the dIVC percentages was $\leq 18 \%$ for all of the positive pressure support hypervolemic groups, apart from the hypervolemic T tube group (19\%) [43].

IVC distensibilty index cut off value $66.5 \%$ to predict weaning failure with sensitivity $100 \%$ and specificity $68.4 \%$, AUC 0.85 in our study.

Few relevant clinical studies on IJV and IVC distensibilty indices to predict weaning induced Cardiac dysfunction, Most of the studies done to evaluate IJV distensibilty index as a substitute to IVC di index as indicator for fluid responsiveness in mechanically ventilated patients. Apart from Baumann et al. found

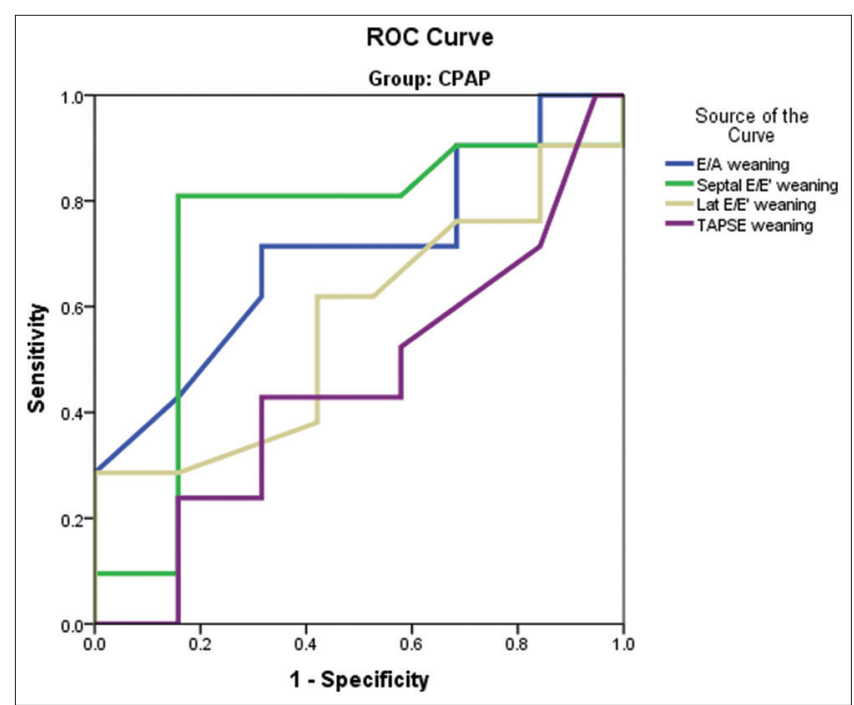

Figure 1: ROC curve analysis for Mitral flow indices during weaning on CPAP and weaning failure 
a good correlation between IVC $\mathrm{Ci}$ and IJV ci in patients with spontaneous respiration; however, they determined that there was no statistically significant correlation when positive pressure ventilation was applied [40]. This was confirmed by our study.

\section{Study limitations}

The study is a single center trial. Relatively with small sample size. Both echocardiography and vascular

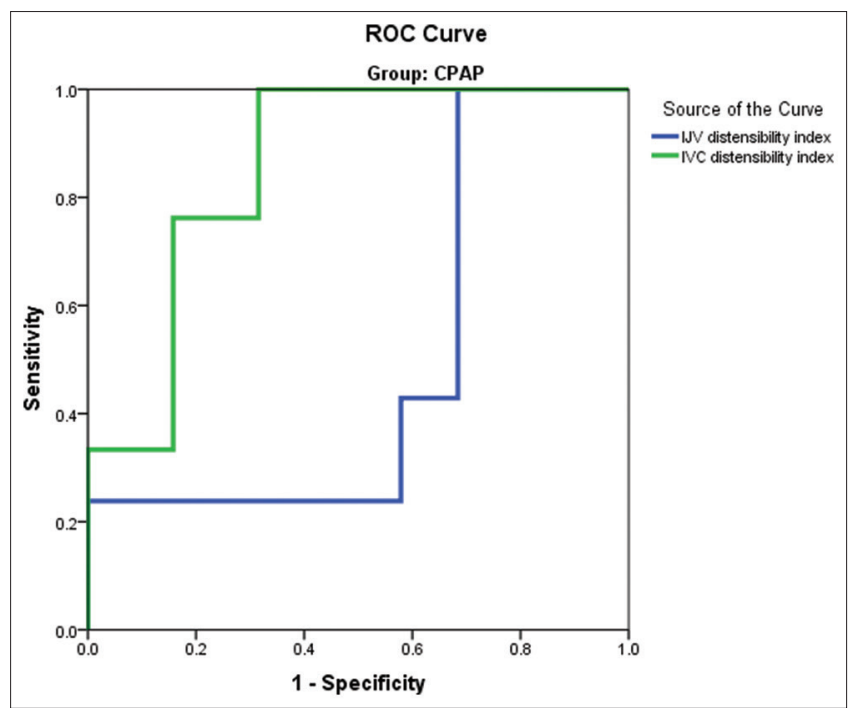

Figure 2: ROC curve for preload indices during weaning during CPAP start spontaneous breathing trial and weaning failure. Mitral Septal E/E' on CPAP was correlated to IVC distensibilty index during weaning on CPAP $(r=0.599, p<0.001)$.

ultrasound are an operator dependent techniques and mechanical ventilation represented a somewhat difficulty during their performance.

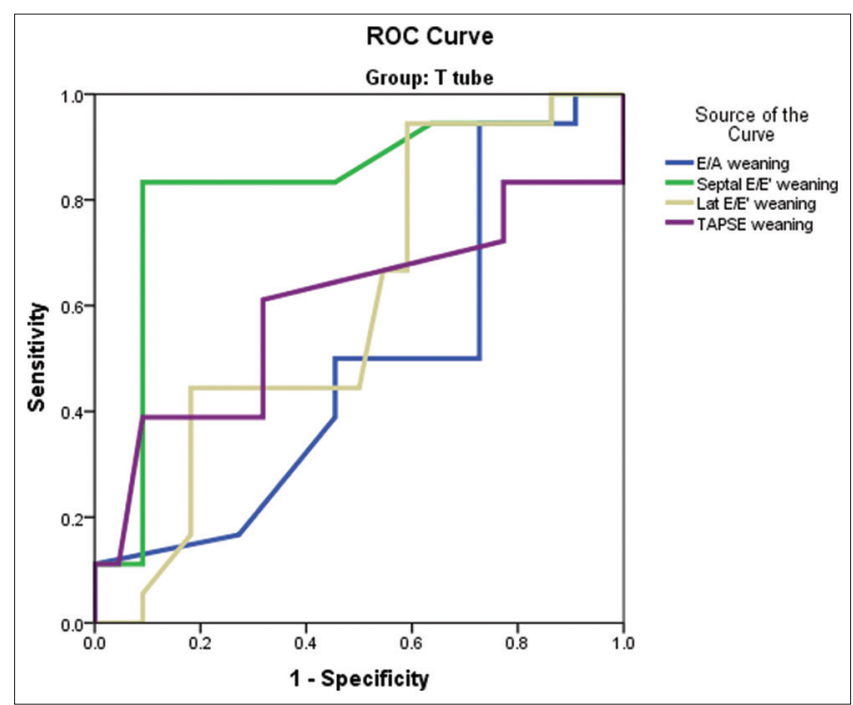

Figure 3: ROC curve analysis for mitral flow indices and TAPSE during weaning on T-piece to predict weaning failure

IJV ultrasonography dictate patients' cooperation which might obscure accurate data interpretation. Some problems like chest wall lesions or obesity might be troublesome during ultrasound evaluation.

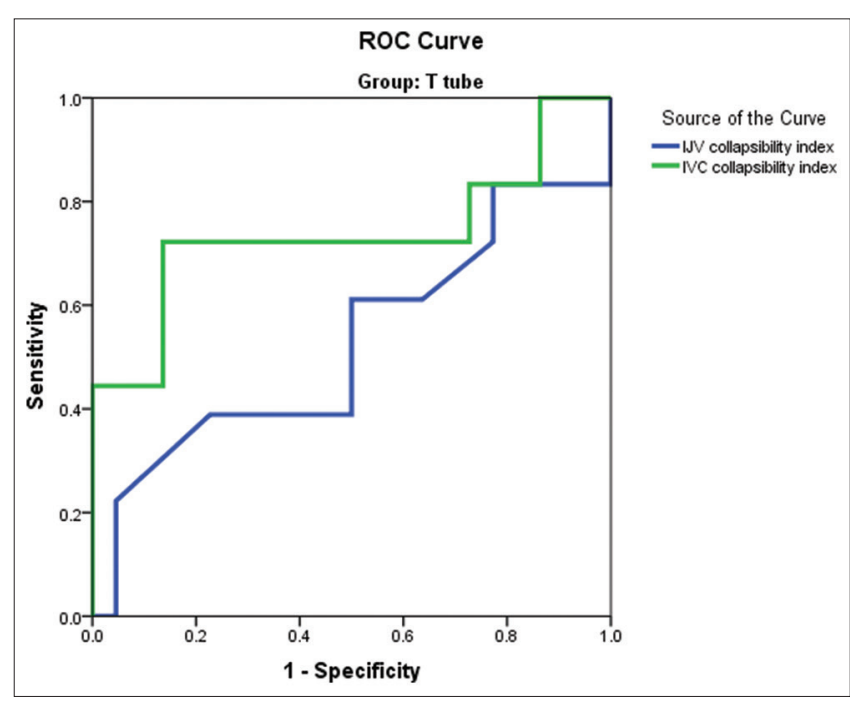

Figure 4: ROC curve showing preload indices during weaning on T-piece.

\section{Conclusion and Recommendations}

Cardiac dysfunction is an important cause of weaning failure. Mitral Septal E/E' could predict weaning induced diastolic dysfunction. IVC plays important role in determining fluid status and predict weaning failure IJV ultrasonography plays minimal role for predicting weaning failure.

RV echocardiographic assessment is inconclusive in predicting weaning failure. Further studies are needed to investigate Respiratory changes in both IJV and inferior vena cava during weaning as predictors of weaning failure.

\section{Acknowledgment}

We are deeply thankful Critical Care Medicine department staff, Cairo University for their great help, patience and outstanding support throughout the practicing this work and handling difficulties and technical support.

\section{References}

1. Hasan A, Hasan A. Ventilator settings. In: Understanding Mechanical Ventilation. Berlin, Germany: Springer; 2010.

2. Constant J. Using internal jugular pulsations as a manometer for right atrial pressure measurements. Cardiology. 2000;93(12):26-30. https://doi.org/10.1159/000006998 


\section{PMid:10894903}

3. Sankoff J, Zidulka A. Non-invasive method for the rapid assessment of central venous pressure: Description and validation by a single examiner. West $\mathrm{J}$ Emerg Med. 2008;9(4):201-5.

PMid: 19561745

4. Conn RD, O'Keefe JH. Simplified evaluation of the jugular venous pressure: Significance of inspiratory collapse of jugular veins. Mo Med. 2012;109(2):150-2.

PMid:22675798

5. Chua Chiaco JM, Parikh NI, Fergusson DJ. The jugular venous pressure revisited. Cleve Clin J Med. 2013;80(10):638-44. https://doi.org/10.3949/ccjm.80a.13039

\section{PMid:24085809}

6. Boles JM, Bion J, Herridge M. Weaning from mechanical ventilation. Eur Respir J. 2007;29(5):1033-56. https://doi. org/10.1183/18106838.0104.281

\section{PMid:17470624}

7. Knaus WA, Wagner DP, Draper EA, Zimmerman JE, Bergner M Bastos PG, et al. The APACHE III prognostic system: Risk prediction of hospital mortality for critically III hospitalized adults. Chest. 1991;100(6):1619-36.

PMid:1959406

8. Singer M, Deutschman CS, Seymour C, Shankar-Hari M, Annane $\mathrm{D}$, Bauer $\mathrm{M}$, et al. The third international consensus definitions for sepsis and septic shock (sepsis-3). JAMA. 2016;315(8):801-10. https://doi.org/10.1001/jama.2016.0288 PMid:26903338

9. Subirà $C$, Hernández G, Vázquez $A$, Rodríguez-Garciá $R$, González-Castro A, Garciá C, et al. Effect of pressure support vs $T$-piece ventilation strategies during spontaneous breathing trials on successful extubation among patients receiving mechanical ventilation: A randomized clinical trial. JAMA. 2019;321(22):2175-82. https://doi.org/10.1001/jama.2019.7234 PMid:31184740

10. McConville JF, Kress JP. Weaning patients from the ventilator N Engl J Med. 2012;367(23):2233-9. PMid:23215559

11. Slama M, Maizel J. Echocardiographic measurement of ventricular function. Curr Opin Crit Care. 2006;12(3):241-8. https://doi.org/10.1097/01.ccx.0000224869.86205.1a PMid:16672784

12. Gottdiener JS, Bednarz J, Devereux R, Gardin J, Klein A Manning WJ, et al. American Society of Echocardiography recommendations for use of echocardiography in clinical trials. J Am Soc Echocardiogr. 2004;17(10):1086-119. https://doi. org/10.1016/s0894-7317(04)00675-3

\section{PMid:15452478}

13. Nagueh SF, Smiseth OA, Appleton CP, Byrd BF, Dokainish H, Edvardsen $\mathrm{T}$, et al. Recommendations for the evaluation of left ventricular diastolic function by echocardiography: An update from the American society of echocardiography and the European association of cardiovascular imaging. Eur Heart J Cardiovasc Imaging. 2016;29(4):277-314. https://doi. org/10.1093/ehjci/jew082

\section{PMid:27037982}

14. Aloia E, Cameli M, D'Ascenzi F, Sciaccaluga C, Mondillo S TAPSE: An old but useful tool in different diseases. Int J Cardiol. 2016;225:177-83. https://doi.org/10.1016/j.ijcard.2016.10.009 PMid:27728861

15. Ilyas A, Ishtiaq W, Assad S, Ghazanfar H, Mansoor S, Haris M, et al. Correlation of IVC diameter and collapsibility index with central venous pressure in the assessment of intravascular volume in critically ill patients. Cureus. 2017;9(2):e1025. https://

\section{doi.org/10.7759/cureus.1025}

\section{PMid:28348943}

16. Barbier $C$, Loubières $Y$, Schmit $C$, Hayon J, Ricôme JL, Jardin $F$ et al. Respiratory changes in inferior vena cava diameter are helpful in predicting fluid responsiveness in ventilated septic patients. Intensive Care Med. 2004;30(9):1740-6. https://doi. org/10.1007/s00134-004-2259-8

PMid:15034650

17. Killu K, Coba V, Huang $Y$, Andrezejewski T, Dulchavsky S Internal jugular vein collapsibility index associated with hypovolemia in the intensive care unit patients. Crit Ultrasound J. 2010; https://doi.org/10.1007/s13089-010-0034-3

18. Zein $H$, Baratloo A, Negida A, Safari S. Ventilator weaning and spontaneous breathing trials; an educational review. Emergency. 2016;2:13-7.

19. Liu J, Shen F, Teboul JL, Anguel N, Beurton A, Bezaz N, et al Cardiac dysfunction induced by weaning from mechanical ventilation: Incidence, risk factors, and effects of fluid removal. Crit Care. 2016;20(1):369. https://doi.org/10.1186/ s13054-016-1533-9

\section{PMid:27836002}

20. Sanfilippo F, Di Falco D, Noto A, Santonocito C, Morelli A, Bignami $\mathrm{E}$, et al. Association of weaning failure from mechanical ventilation with transthoracic echocardiography parameters: A systematic review and meta-analysis. $\mathrm{Br} J$ Anaesth. 2021;126(1):319-30. https://doi.org/10.1016/j.bja.2020.07.059 PMid:32988600

21. Ely EW, Shintani A, Truman B, Speroff T, Gordon SM, Harrell FE, et al. Delirium as a predictor of mortality in mechanically ventilated patients in the intensive care unit. $\mathrm{J}$ Am Med Assoc. 2004;291(14):1753-62. https://doi.org/10.1001/ jama.291.14.1753

PMid: 15082703

22. Moschietto S, Doyen D, Grech L, Dellamonica J, Hyvernat H Bernardin G. Transthoracic echocardiography with doppler tissue imaging predicts weaning failure from mechanical ventilation: Evolution of the left ventricle relaxation rate during a spontaneous breathing trial is the key factor in weaning outcome. Crit Care. 2012;16(3):R81. https://doi.org/10.1186/ cc11339

PMid:22583512

23. Schifelbain LM, Vieira SR, Brauner JS, Pacheco DM, Naujorks AA. Echocardiography-Doppler evaluation during weaning process. Ann Intensive Care. 2018;8(1):7. http://dx.doi. org/10.1186/s13613-017-0345-7

24. Rojek-Jarmuła A, Hombach R, Krzych ŁJ. APACHE II score predicts mortality in patients requiring prolonged ventilation in a weaning center. Anaesthesiol Intensive Ther. 2016;48(4):215-9. https://doi.org/10.5603/ait.a2016.0036 PMid:27595745

25. Bien U, Peres Costa I, Arena LS. Identifying apache ii and sofa threshold values that predict successful weaning and extubation from mechanical ventilation. Am J Respir Crit Care Med. 2016;193:5295.

26. Metwally A, El-Sokary R, Abd-Latif H,Ahmed G. Pressure support ventilation (PSV) mode vs. (PSV)mode + T-piece trial as a weaning modality in mechanically ventilated chronic obstructive pulmonary disease patients. Eur Respirat J. 2018;52:PA2336. https://doi.org/10.1183/13993003.congress-2018.pa2336

27. Schifelbain LM, Vieira SR, Brauner JS, Pacheco DM Naujorks AA. Echocardiographic evaluation during weaning from mechanical ventilation. Clinics. 2011;66(1):107-11. https:// doi.org/10.1590/s1807-59322011000100019 PMid:21437445

28. Prospective observational study on evaluation of cardiac 
dysfunction induced during the weaning process. Indian J Crit Care Med. 2019;23(1):15-9.

PMid:31065203

29. Haji K, Haji D, Canty DJ, Royse AG, Green C, Royse CF. The impact of heart, lung and diaphragmatic ultrasound on prediction of failed extubation from mechanical ventilation in critically ill patients: A prospective observational pilot study. Crit Ultrasound J. 2018;10(1):13. https://doi.org/10.1186/s13089-018-0096-1 PMid:29971618

30. Caille V, Amiel JB, Charron C, Belliard G, Vieillard-Baron A, Vignon P. Echocardiography: A help in the weaning process. Crit Care. 2010;14(3):R120. https://doi.org/10.1186/cc9076 PMid:20569504

31. Papanikolaou J, Makris D, Saranteas T, Karakitsos D, Zintzaras E, Karabinis A, et al. New insights into weaning from mechanical ventilation: Left ventricular diastolic dysfunction is a key player. Intensive Care Med. 2011;37(12):1976-85. https:// doi.org/10.1007/s00134-011-2368-0

PMid:21976188

32. Lamia B, Maizel J, Ochagavia A, Chemla D, Osman D, Richard C, et al. Echocardiographic diagnosis of pulmonary artery occlusion pressure elevation during weaning from mechanical ventilation. Crit Care Med. 2009;37(5):1696-701. https://doi.org/10.1097/ccm.0b013e31819f13d0 PMid:19325473

33. Maragiannis D, Nagueh SF. Echocardiographic evaluation of left ventricular diastolic function: An update. Curr Cardiol Rep. 2015;17(2):3. https://doi.org/10.1007/s11886-014-0561-9 PMid:25618306

34. Haji DL, Ali MM, Royse A, Canty DJ, Clarke S, Royse CF. Interatrial septum motion but not doppler assessment predicts elevated pulmonary capillary wedge pressure in patients undergoing cardiac surgery. Anesthesiology. 2014;121(4):71929. https://doi.org/10.1097/aln.0000000000000392 PMid:25089641

35. Konomi I, Tasoulis A, Kaltsi I, Karatzanos E, Vasileiadis I, Temperikidis $\mathrm{P}$, et al. Left ventricular diastolic dysfunction-an independent risk factor for weaning failure from mechanical ventilation. Anaesth Intensive Care. 2016;44(4):466-73. https:// doi.org/10.1177/0310057×1604400408

PMid:27456176

36. Saeed AM, Elshahed GS, Osman NM, Gomaa AA, Fahyim SM. Study of diaphragmatic mobility by chest ultrasound and echocardiographic changes in chronic obstructive pulmonary disease patients on different modes of mechanical ventilation. Egypt J Bronchol. 2018;13:399-404. https://doi.org/10.4103/ejb. ejb_99_18

37. Da Costa AD, De Mello Rieder M, Vieira SR. Weaning from mechanical ventilation by using pressure support or T-tube ventilation. Comparison between patients with and without heart disease. Arq Bras Cardiol. 2005;85(1):32-8.

PMid:16041452

38. El Morttada A, Moteleb A. Using echocardiography and chest ultrasound for guidance of management of difficult-to-wean COPD patients. J Cardiol Curr Res. 2018;11(4):178-84. https:// doi.org/10.15406/jccr.2018.11.00394

39. Airapetian N, Maizel J, Alyamani O, Mahjoub Y, Lorne E, Levrard $\mathrm{M}$, et al. Does inferior vena cava respiratory variability predict fluid responsiveness in spontaneously breathing patients? Crit Care. 2015;19:400. https://doi.org/10.1186/ s13054-015-1100-9 PMid:26563768

40. Bauman Z, Coba V, Gassner M, Amponsah D, Gallien J, Blyden $\mathrm{D}$, et al. Inferior vena cava collapsibility loses correlation with internal jugular vein collapsibility during increased thoracic or intra-abdominal pressure. J Ultrasound. 2015;18(4):343-8 https://doi.org/10.1007/s40477-015-0181-2 PMid:26550073

41. Juhl-Olsen P, Frederiksen CA, Sloth E. Ultrasound assessment of inferior vena cava collapsibility is not a valid measure of preload changes during triggered positive pressure ventilation: A controlled cross-over study. Ultraschall Med. 2012;33(2):152-9 https://doi.org/10.1055/s-0031-1281832

PMid:22179799

42. Tongyoo S, Thomrongpairoj P, Permpikul C. Efficacy of echocardiography during spontaneous breathing trial with lowlevel pressure support for predicting weaning failure among medical critically ill patients. Echocardiography. 2019;36(4):65965. https://doi.org/10.1111/echo.14306

PMid: 30834600

43. Saritaş A, Zincircioğlu Ç, Uzun Saritaş P, Uzun U, Köse I, Şenoğlu N. Comparison of inferior vena cava collapsibility, distensibility, and delta indices at different positive pressure supports and prediction values of indices for intravascular volume status. Turkish J Med Sci. 2019;49(4):1170-8. https:// doi.org/10.3906/sag-1810-52

PMid:31340632 